\title{
Herramientas GNSS en la Enseñanza de Geografía y Cartografía: Aspectos Metodológicos
}

\section{GNSS Tools Used in Teaching Geography and Cartography: Methodological Aspects}

\author{
Bepsy Cedeño-Montoya ${ }^{1}$ \\ Consuelo Alfaro-Chavarría \\ Universidad Nacional, Costa Rica
}

http://dx.doi.org/10.15359/rgac.61-2.3

\begin{abstract}
RESUMEN
El artículo presenta los principales aspectos metodológicos adquiridos a lo largo de los dos años de ejecución del proyecto "Aplicación de la herramienta GPS en la enseñanza de Cartografía". Se describe la metodología utilizada, detallando los procesos y pasos seguidos para cumplir con los objetivos, tareas y actividades propuestas en la formulación del proyecto. Se describen las distintas fases técnicas, indicando los programas y herramientas utilizadas, así como las principales dificultades enfrentadas en cada proceso. Además, se muestran los principales productos generados: el banco de datos espaciales puntuales de alta precisión, el mosaico de fotografías aéreas georreferenciadas y el mosaico de imágenes ortorectificadas, se realiza un análisis de los resultados obtenidos y se presentan las principales conclusiones y recomendaciones derivadas del proceso desarrollado.
\end{abstract}

Palabras clave: GPS, datos GNSS, georreferencia, ortorectificación, docencia.

1 Máster y Académica en la Escuela de Ciencias Geográficas, Universidad Nacional de Costa Rica. Correo electrónico: bepsy.cedeno.montoya@una.cr

2 Máster y Académica en la Escuela de Ciencias Geográficas, Universidad Nacional de Costa Rica. Correo electrónico: consuelo.alfaro.chavarria@una.cr

Fecha de recepción: 2 agosto de 2017

Fecha de aceptación: 23 de enero de 2018 


\begin{abstract}
The article presents the main methodological aspects acquired during the two years of execution of the project "Application of the GPS tool in the teaching of Cartography". It describes the methodology used, detailing the processes and steps followed to meet the objectives, tasks and activities proposed in the formulation of the project. It describes the different technical phases, indicating the programs and tools used, as well as the main difficulties faced in each process. In addition, the main products are shown: the high precision point spatial data bank, the mosaic of georeferenced aerial photographs and the mosaic of orthorectified images, performing an analysis of the results obtained and presenting the main conclusions and recommendations derived from the methodological process developed.
\end{abstract}

Keywords: GPS, GNSS data, georeferenced, orthorectification, docenc

\title{
Introducción
}

En el 2014, se formuló en la Escuela de Ciencias Geográficas (ECG) de la Universidad Nacional de Costa Rica (UNA), un proyecto de docencia que buscaba contribuir con la generación de datos espaciales de alta precisión y con la capacitación de parte del personal docente del área de Cartografía, SIG y Teledetección. Lo anterior, tras detectar un vacío en materia de utilización y aplicación de datos proveniente de GPS en los planes de estudio de las carreras de Bachillerato en Ciencias Geográficas con énfasis en ordenamiento del territorio y el Diplomado en Cartografía y Diseño Digital.

El proyecto fue aprobado y se ejecutó durante el 2015 y 2016. Su objetivo general fue generar una metodología para la utilización del equipo GPS Trimble ${ }^{\circledR}$ R4 y el controlador Trimble ${ }^{\circledR}$ TSC 2 en levantamientos de datos de alta precisión, que permitan georreferenciar y ortorectificar fotografías aéreas y generar productos cartográficos.

Las tareas identificadas como necesarias para cumplir con cada uno de los objetivos específicos del proyecto fueron cumplidas en su totalidad, por lo que ahora se cuenta con una serie de datos, generados a partir de mediciones en el Sistema Global de Navegación por Satélite (GNSS por sus siglas en inglés), como coordenadas de alta precisión, fotografías georreferenciadas y ortorectificadas, mapas temáticos y una unidad didáctica en la que se describen con detalle los procedimientos a seguir para utilizar el equipo con que cuenta la ECG. El realizar este tipo de mediciones y realizar el post procesamiento de los datos, dieron como resultado una importante cantidad de material que puede ser utilizado en diferentes cursos y actividades que se desarrollen en la unidad académica. 
Bepsy Cedeño-Montoya, Consuelo Alfaro-Chavarría. Herramientas GNSS en la Enseñanza de Geografía y Cartografía: Aspectos Metodológicos

\section{Metodología}

La metodología fue desarrollada en cinco etapas: capacitación, trabajo de campo Post-procesamiento, Georreferencia y Ortorectificación, que se detallan a continuación.

\section{Etapa 1: Capacitación}

El proyecto inició en el mes de enero de 2015 con una capacitación rápida en la que se repasaron las características básicas del equipo GNSS que posee la ECG y los tipos de medición que pueden realizarse con el mismo, además, se revisó la licencia del software de procesamiento, se actualizó el firmware de los receptores y el programa Survey Controller y la configuración de los métodos de observación definidos en el software del controlador.

La ECG ya contaba con un equipo Trimble ${ }^{\circledR}$ R4 GNSS (ver figura 1), con el software de campo Survey Controller, instalado en el controlador TSC2 y una licencia del programa de post-procesamiento Trimble ${ }^{\circledR}$ Business Center (TBC, versión 2.5).

Figura 1: equipo Trimble ${ }^{\circledR}$ R4 GNSS y controlador TSC2.

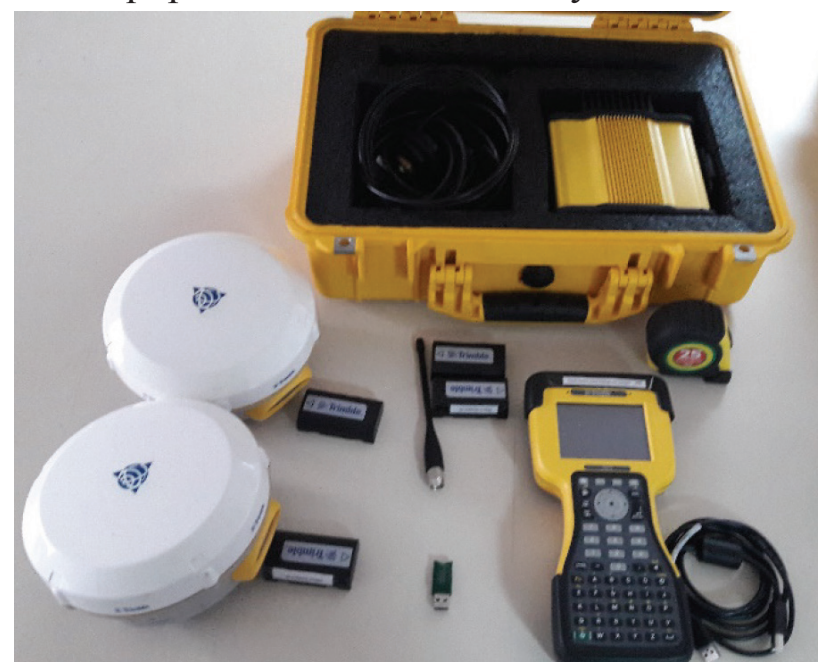

Fuente: Foto de equipo Trimble ${ }^{\circledR}$ R4 GNSS y controlador TSC2 de la Escuela Ciencias Geográficas, 2015. 
Según la hoja de datos de Trimble®, el equipo R4 rastrea simultáneamente señales de satélite GPS L1, L2, L2C y QZSS, además, permite actualizar a GLONASS, Galileo, y BeiDou (COMPASS), facilitando mediciones GNSS con precisión horizontal $3 \mathrm{~mm}+0,1 \mathrm{ppm}$ RMS y vertical de 3,5 mm + 0,4 ppm RMS en estáticos de alta precisión, con una precisión horizontal de $8 \mathrm{~mm}+1 \mathrm{ppm}$ RMS y vertical de $15 \mathrm{~mm}+1$ ppm RMS en redes RTK.

Este equipo había sido utilizado únicamente en prácticas de algunos cursos del Programa de Maestría en Sistemas de Información Geográfica y Teledetección, por lo que se consideró que estaba subutilizado.

El proyecto "Aplicación de la herramienta GPS en la enseñanza de Cartografía" realizó las primeras pruebas de medición en el Campus Omar Dengo durante el mes de marzo de 2015. El ejercicio fue de gran aprendizaje para identificar problemas en el trabajo de campo y en el procesamiento de los datos, entre los que se encontraban que los sitios de medición seleccionados resultaron no ser los ideales, dificultades en la descarga de los datos por inexperiencia en el manejo de los formatos, y principalmente, en el manejo del software de post-procesamiento, debido a desconocimiento de nociones básicas de geodesia.

Ante las dificultades enfrentadas, se decidió solicitar capacitación y asesoramiento al Centro Nacional de Procesamiento de Datos Geoespaciales (CNPDG) de la Escuela de Topografía Catastro y Geodesia (ETCG) de la UNA.

Los datos generados durante la medición realizada en el mes de marzo fueron de gran utilidad para esta capacitación, permitiendo que los participantes del proyecto se concentraran en aprender sobre datos de alta precisión y equipos GNSS, definición de redes para la medición, la planificación del trabajo de campo, las mediciones y post-proceso de los datos brutos.

Se redefinieron las redes de medición en el Campus Omar Dengo y en el distrito primero del cantón Central de Heredia, considerando la cantidad y características del equipo disponible, las distancias y desplazamientos entre los sitios de medición, la cantidad de personas que participarían del trabajo de campo, el uso que se le daría a las coordenadas en el resto del proyecto, entre otros aspectos. Se generaron una serie de plantillas a utilizar en el trabajo de campo como fichas para la planificación y control del trabajo de campo y las mediciones. 
Bepsy Cedeño-Montoya, Consuelo Alfaro-Chavarría. Herramientas GNSS en la Enseñanza de Geografía y Cartografía: Aspectos Metodológicos

\section{Etapa 2: Trabajo de campo}

En el 2015 se llevaron a cabo dos nuevos levantamientos de datos, utilizando mediciones de tipo estático, el de la red del Campus Omar Dengo que se realizó en los meses de julio y agosto, y el de la red del distrito Heredia efectuada en agosto. Se levantaron un total de 14 puntos de control distribuidos de la siguiente forma:

- Red Heredia: se establecieron siete puntos de medición en el distrito primero del cantón Central de Heredia. Se definió como base un punto ubicado en El Fortín y los otros se ubicaron en el Colegio Humanista de la UNA, la Escuela Cleto González Víquez, el Polideportivo de Barrio Fátima, el Palacio de los Deportes, el Polideportivo de San Francisco y el parque infantil de la Urbanización Miraflores (ver mapa 1). El trabajo de campo se realizó los días 24 y 31 de julio de 2015.

- Red Campus Omar Dengo: también se definieron 7 sitios de medición, con una base establecida en la Plaza de la Diversidad. Los restantes seis puntos de ubicaron en el parqueo de la Facultad de Ciencias Sociales, el Centro de Estudios Generales, el puente de la Escuela de Ciencias Geográficas, el parqueo de la Escuela de Ciencias Biológicas, el parqueo de la Escuela de Música y en la Estación Meteorológica de la Escuela de Física. (ver mapa 2). Este levantamiento se realizó los días 7 y 21 de agosto de 2015.

Para ambas redes se realizaron mediciones bajo el método de observación estático, estableciendo para la base tiempos de medición de aproximadamente 8 horas y de 30 minutos para cada uno de los otros seis puntos. Los levantamientos se realizaron en dos días distintos, pues las redes fueron configuradas de forma tal que en un día se midiera desde la base hacia los puntos periféricos, y que en el segundo día las mediciones se realizan entre puntos.

Los datos brutos obtenidos fueron descargados en el controlador tras cada medición, y posteriormente en una computadora, en la cual fueron procesados. 
Bepsy Cedeño-Montoya, Consuelo Alfaro-Chavarría. GNSS Tools Used in Teaching Geography and Cartography: Methodological Aspects

Mapa 1: Distribución de los puntos de control de la Red Heredia

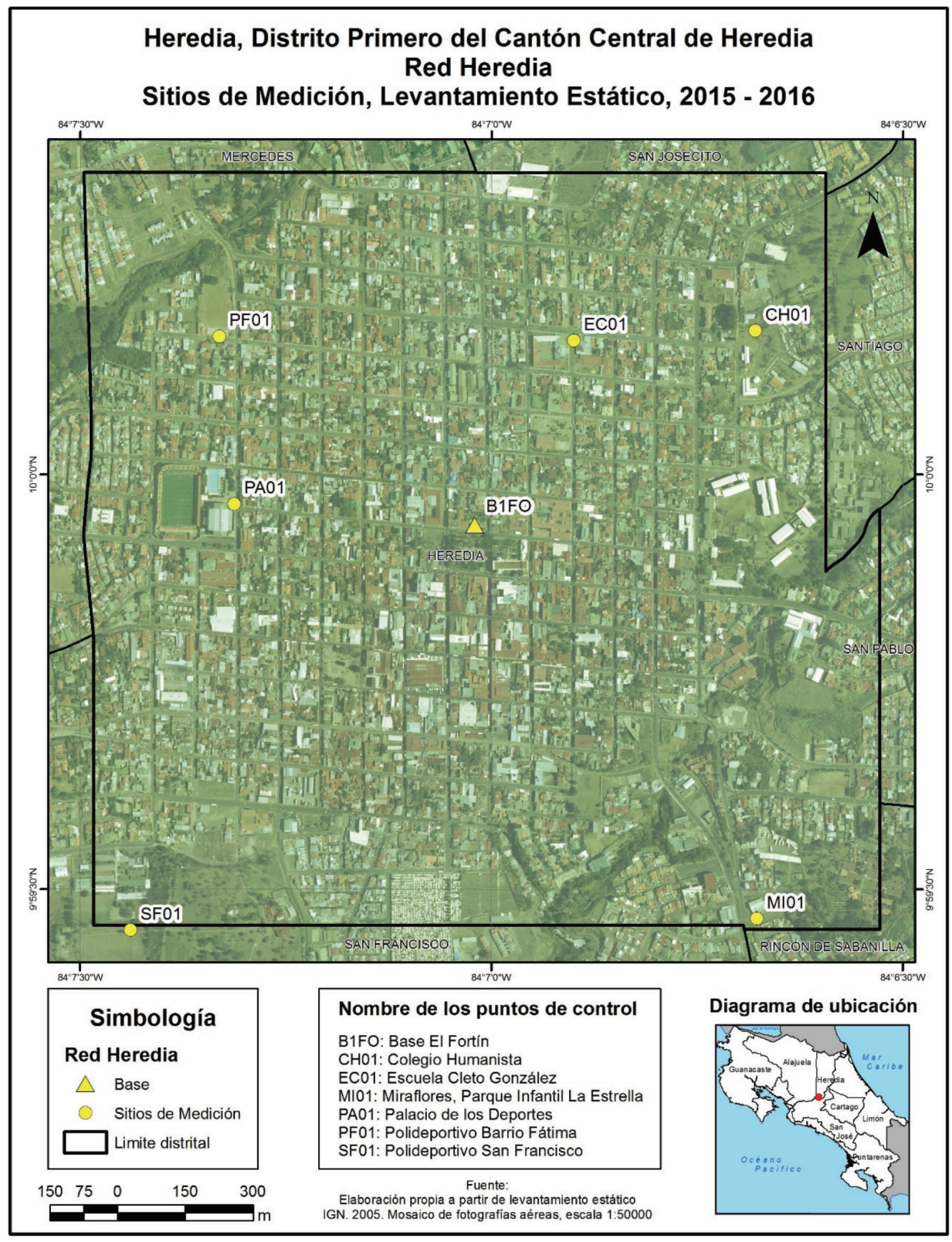


Bepsy Cedeño-Montoya, Consuelo Alfaro-Chavarría. Herramientas GNSS en la Enseñanza de Geografía y Cartografía: Aspectos Metodológicos

Mapa 2: Distribución de los puntos de control de la Red Campus Omar Dengo.

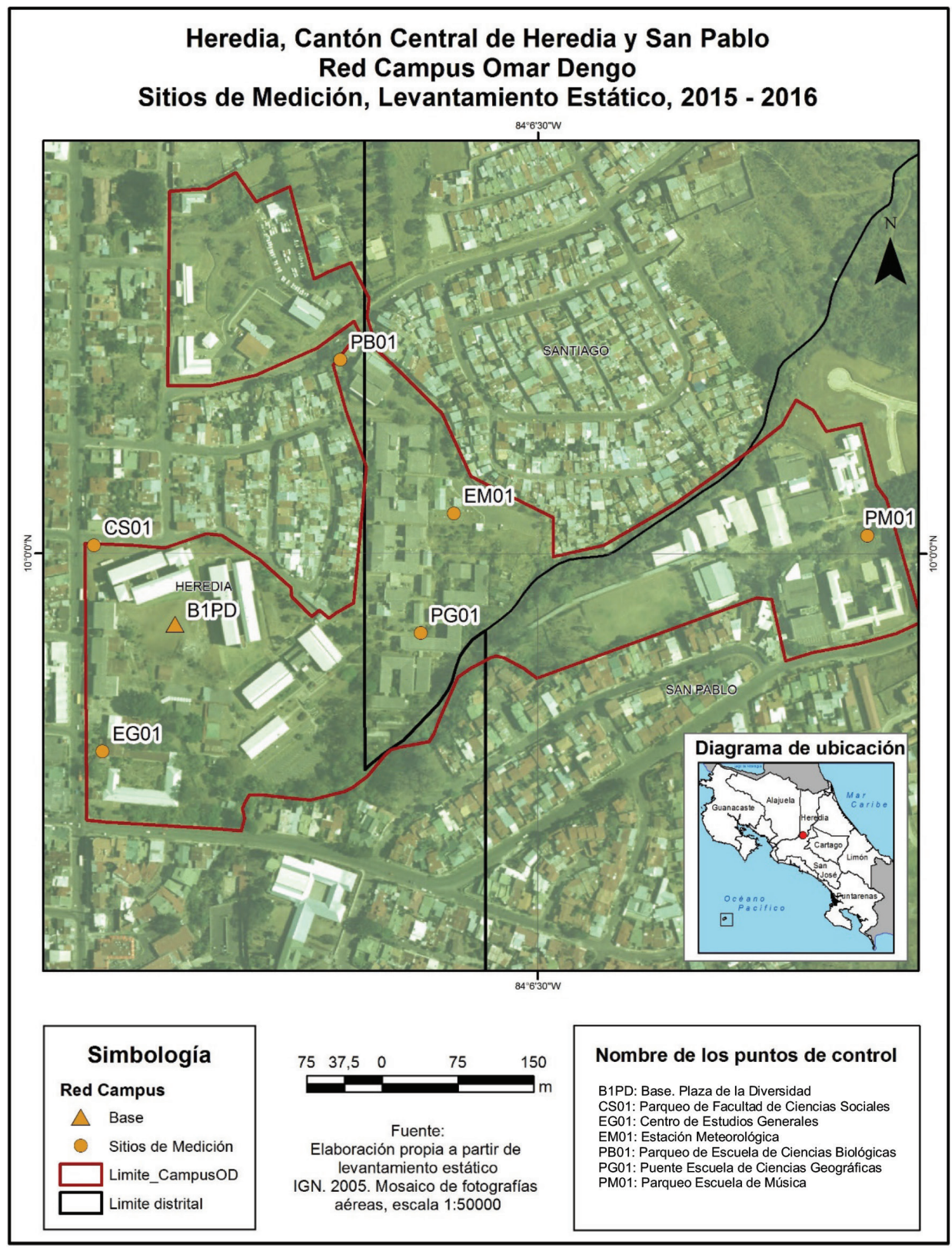




\section{Etapa 3: Post-procesamiento}

El post-procesamiento de los datos se realizó utilizando el software Trimble ${ }^{\circledR}$ Business Center (TBC), versión 2.5, que funciona mediante una llave de hardware HASP ${ }^{\circledR}$ conectada a un puerto USB del equipo.

Se trabajaron de forma separada para los datos de la Red Heredia y la Red Campus Omar Dengo, es decir, el procedimiento que a continuación se detalla se ejecutó en dos ocasiones.

Se inició con la creación de un nuevo proyecto en el programa TBC y la definición del sistema de coordenadas, coincidente con el sistema en el que se encontraban los datos adquiridos en el levantamiento. En el caso de este proyecto los datos fueron adquiridos en el sistema CRTM05, cuyos parámetros estaban incluidos en el software del controlador, no así en el TBC.

De seguido se realizó la importación de los datos brutos hacia el programa, haciendo una conexión a la carpeta que contenía los datos y seleccionando los archivos de interés (figura 2) (formato *.T01, *.T02, ambos nativos de Trimble $\left.{ }^{\circledR}\right)$.

Figura 2: Resumen de la importación de los datos brutos del 24 de julio de 2015, correspondientes a la Red Heredia.

\begin{tabular}{|c|c|c|c|c|c|c|}
\hline \multicolumn{7}{|c|}{ Vista de puntos } \\
\hline \multicolumn{2}{|c|}{ Importar } & ID punto & Nombre de archivo & Hora de inicio & Hora final & Duración \\
\hline - & $\nabla$ & $\mathrm{B} 1 \mathrm{FO}$ & 04522050.T01 & 24/07/2015 08:40:15 a.m. & 24/07/2015 01:23:15 p.m. & 04:43:00 \\
\hline & $\nabla$ & $\mathrm{CH} 01$ & 09842050.T01 & 24/07/2015 08:57:45 a.m. & 24/07/2015 09:29:15 a.m. & $00: 31: 30$ \\
\hline & $\nabla$ & $\mathrm{EC} 01$ & 09842051.T01 & 24/07/2015 09:38:45 a.m. & 24/07/2015 10:09:45 a.m. & 00:31:00 \\
\hline & $\nabla$ & PF01 & 09842052.T01 & 24/07/2015 10:17:45 a.m. & 24/07/2015 10:47:45 a.m. & 00:30:00 \\
\hline & $\nabla$ & PA01 & 09842053.T01 & 24/07/2015 10:56:15 a.m. & 24/07/2015 11:26:15 a.m. & 00:30:00 \\
\hline & $\nabla$ & SF01 & 09842054.T01 & 24/07/2015 11:46:45 a.m. & 24/07/2015 12:17:15 p.m. & $00: 30: 30$ \\
\hline & $\nabla$ & MI01 & 09842055.T01 & 24/07/2015 12:41:45 p.m. & 24/07/2015 01:12:15 p.m. & $00: 30: 30$ \\
\hline
\end{tabular}

Fuente: Elaboración propia a partir del resumen de importación de datos del programa TBC.

Durante el proceso de importación se prestó atención a aspectos reseñados en las cejillas Punto, Antena y Receptor, pues enlistan los archivos importados y sus características respectivas, ofreciendo la posibilidad de detectar errores o faltantes de información, y de pensar aquí en formas de solventarlo, mediante nuevos levantamientos o utilizando datos de estaciones de apoyo.

El producto de las mediciones es una red estática que "describe la geometría y el orden en el que se organizan y procesan las líneas base GPS 
Bepsy Cedeño-Montoya, Consuelo Alfaro-Chavarría. Herramientas GNSS en la Enseñanza de Geografía y Cartografía: Aspectos Metodológicos

capturadas mediante las técnicas estática y FastStatic [...] El resultado es un conjunto de líneas base que se deriva utilizando coordenadas iniciales precisas" (Trimble $\left.{ }^{\circledR}, 2005: 103\right)$.

Figura 3: Puntos y líneas base de la Red Heredia desplegados en la vista del TBC.

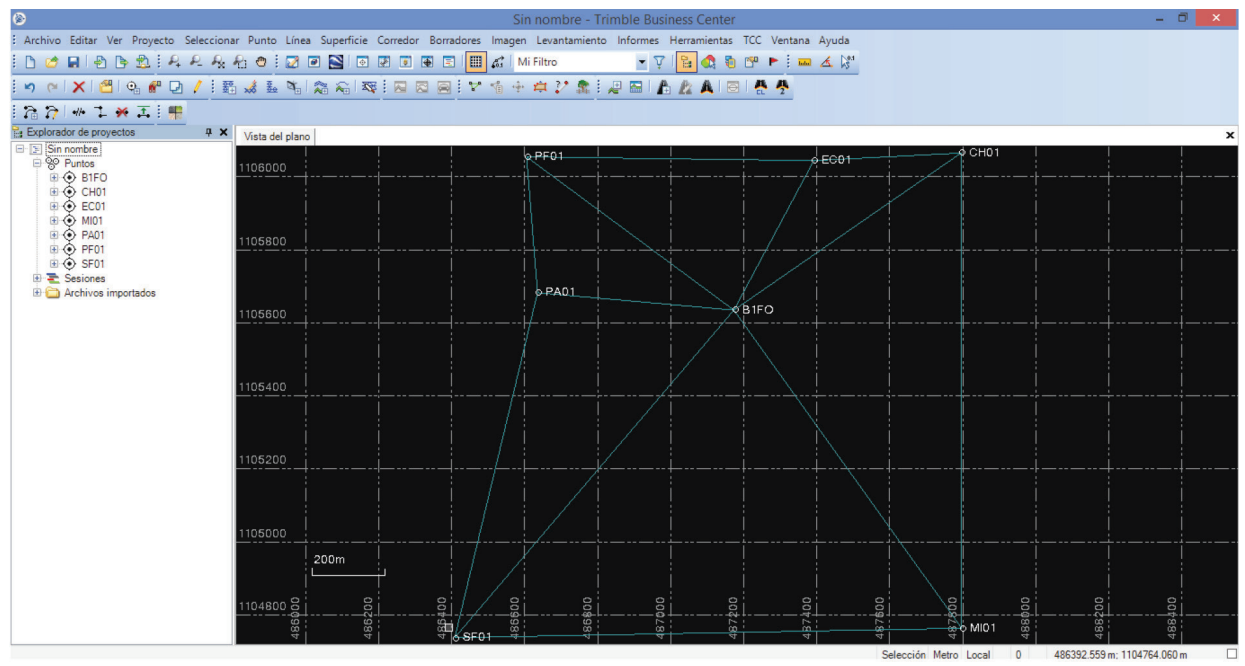

Fuente: Elaboración propia a partir de la visualización de los puntos y las líneas base en el programa TBC.

Lo que se busca con el post-procesamiento es corregir los datos brutos generados en el trabajo de campo, a partir de otros datos que sean aún más precisos y confiables. Estos datos provienen de las estaciones de medición continua más próximas al área de estudio, para el caso de Costa Rica se cuenta con información de las estaciones del Instituto Geográfico Nacional (IGN) y de la red SIRGAS.

A continuación en la tabla 1 se detallan las estaciones de medición continúa utilizadas en este proyecto: 
Tabla 1: Estaciones de medición continua utilizadas en el proyecto.

\begin{tabular}{|l|l|l|}
\hline $\begin{array}{l}\text { Nombre de } \\
\text { la estación }\end{array}$ & \multicolumn{1}{|c|}{ Institución a cargo } & $\begin{array}{l}\text { Red a la que } \\
\text { pertenece }\end{array}$ \\
\hline AACR & Instituto Nacional de Acueductos y Alcantarillados (AyA) & SIRGAS \\
\hline CRCP & Centro Nacional de Alta Tecnología (CeNAT) & SIRGAS \\
\hline ETCG & Universidad Nacional (UNA) & SIRGAS \\
\hline RIDC & Instituto Geográfico Nacional (IGN) & IGN \\
\hline
\end{tabular}

Fuente: Elaboración propia con datos de estaciones SIRGAS de operación continua, http://www. sirgas.org/es/sirgas-con-network/stations/station-list/

Las coordenadas de cada estación para las fechas de levantamiento fueron descargadas utilizando el sistema SpiderWeb del Registro Nacional y mediante un servicio FTP que ofrece el CeNAT para las estaciones SIRGAS de Costa Rica.

Los datos de las estaciones de medición continua deben corresponder a las fechas de las mediciones realizadas en campo, por lo que fue necesario conocer el día y semana GPS de los levantamientos. Esta consulta se realizó en el calendario GNSS (Jahic, 2016). Por ejemplo, (figura 4) una de las mediciones en el campo se llevó a cabo el 24 de julio de 2015, fecha que corresponde al día GPS 205 y a la semana GPS 1854.

Figura 4: Visualización de consulta al Calendario GNSS.

\begin{tabular}{|llll|}
\hline \multicolumn{4}{|c|}{ Friday, July 24, 2015 (UTC) } \\
Julian Day Number: & 2457227.5 & Day of Year: & 205 \\
GPS Week: & 1854 & GPS Week Number: & 18545
\end{tabular}

Fuente: Calendario GNSS http://www.gnsscalendar.com/

A continuación, la tabla 2 muestra el día GNSS correspondiente a las fechas en que se realizaron las mediciones de la Red Heredia y el Campus Omar Dengo (COD), con los nombre de los archivos descargados de las estaciones de medición continua, los cuales se importaron al TBC siguiendo el mismo proceso que los datos brutos. 
Bepsy Cedeño-Montoya, Consuelo Alfaro-Chavarría. Herramientas GNSS en la Enseñanza de Geografía y Cartografía: Aspectos Metodológicos

Tabla 2: Fechas de las mediciones y sus correspondientes días según calendario GNSS, junto con el nombre de cada archivo descargado de las estaciones de medición continúa.

\begin{tabular}{|l|l|l|c|c|c|c|}
\hline \multicolumn{1}{|c|}{ Red } & Fechas de Medición & Día GNSS & AACR & CRCP & ETCG & RIDC \\
\hline Heredia & 24 de julio & 205 & AACR2050 & CRCP2050 & ETCG2050 & ridc205o00 \\
\hline Heredia & 31 de julio & 212 & AACR2120 & CRCP2120 & ETCG2120 & ridc212o00 \\
\hline COD & 7 de agosto & 219 & AACR2190 & CRCP2190 & ETCG2190 & ridc219o00 \\
\hline COD & 21 de agosto & 233 & AACR2330 & No se generó & ETCG2330 & ridc233o00 \\
\hline
\end{tabular}

Fuente: Elaboración propia a partir de datos descargados.

A continuación en la figura 5 se muestra un resumen de la importación de los datos de estaciones de medición continúa del 24 y 31 de julio de 2015, correspondientes a la Red Heredia y en la figura 6 se presentan los puntos y líneas base de la Red Heredia y estaciones de medición continua desplegados en la vista del TBC.

Figura 5: Resumen de la importación de los datos de estaciones de medición continúa del 24 y 31 de julio de 2015 , correspondientes a la

Red Heredia.

\begin{tabular}{|c|c|c|c|c|c|c|}
\hline \multirow{3}{*}{\multicolumn{2}{|c|}{ Importar }} & \multirow[b]{2}{*}{ ID punto } & \multicolumn{4}{|c|}{ Vista de puntos } \\
\hline & & & \multirow{2}{*}{$\begin{array}{l}\text { Nombre de archivo } \\
\text { aacr2050.150 }\end{array}$} & \multirow{2}{*}{$\begin{array}{c}\text { Hora de inicio } \\
\text { 23/07/2015 05:59:45 p.m. }\end{array}$} & \multirow{2}{*}{$\begin{array}{c}\text { Hora final } \\
\text { 24/07/2015 05:59:40 p.m. }\end{array}$} & \multirow{2}{*}{$\begin{array}{l}\text { Duración } \\
\text { 23:59:55 }\end{array}$} \\
\hline & & AACR & & & & \\
\hline & $\nabla$ & AACR & aacr 2120.150 & 30/07/2015 05:59:45 p.m. & 31/07/2015 05:59:40 p.m. & $23: 59: 55$ \\
\hline \multirow[t]{6}{*}{ - } & $\nabla$ & RIDC & ridc205000.150 & 24/07/2015 07:59:45 a.m. & 24/07/2015 03:59:30 p.m. & $07: 59: 45$ \\
\hline & $\nabla$ & RIDC & ridc 212000.150 & 31/07/2015 07:59:45 a.m. & 31/07/2015 03:59:30 p.m. & $07: 59: 45$ \\
\hline & $\nabla$ & CRCP & CRCP2050.15o & 23/07/2015 05.59:45 p.m. & 24/07/2015 05:59:15 p.m. & $23: 59: 30$ \\
\hline & $\nabla$ & ETCG & ETCG2050.150 & 23/07/2015 05:59:45 p.m. & 24/07/2015 05:59:15 p.m. & $23: 59: 30$ \\
\hline & $\nabla$ & CRCP & CRCP2120.150 & 30/07/2015 05:59:45 p.m. & 31/07/2015 05:59:15 p.m. & $23: 59: 30$ \\
\hline & $\nabla$ & ETCG & ETCG2120.150 & 30/07/2015 05:59:45 p.m. & 31/07/2015 05:59:15 p.m. & $23: 59: 30$ \\
\hline
\end{tabular}

Fuente: Elaboración propia a partir del resumen de importación de datos del programa TBC. 
Figura 6: Puntos y líneas base de la Red Heredia y estaciones de medición continua desplegados en la vista del TBC.

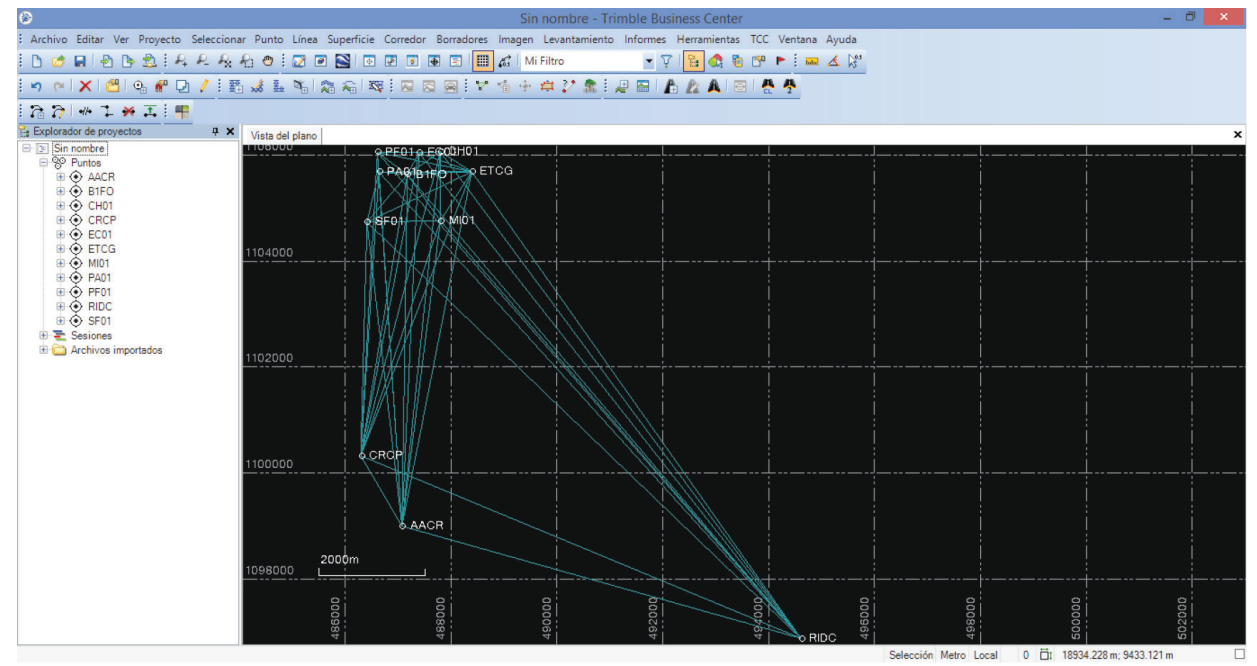

Fuente: Elaboración propia a partir de la visualización de los puntos y las líneas base en el programa TBC.

Adicionalmente en la tabla 3, y con el mismo objetivo de incrementar la precisión de las coordenadas de los sitios o puntos medidos, se incorporaron las efemérides al post-procesamiento. Las efemérides describen la órbita de cada satélite por un espacio de tiempo, calculada por el satélite en base a una serie de parámetros y ecuaciones (García, 2008). Las mismas pueden ser de navegación (transmitidas) o precisas y se definen como:

- Efemérides de navegación: posiciones teóricas de los satélites, las cuales se insertan dentro del mensaje de navegación, siendo posible que sean transmitidas en tiempo real.

- Efemérides precisas: describen las posiciones reales de los satélites, obtenidas a partir del seguimiento continuo de las estaciones del segmento control. Tales efemérides son obtenidas a partir de un post-procesado y están disponibles unos días más tarde. Son más exactas que las de navegación, pues se corresponden con posiciones reales y no teóricas de los satélites (Comisión Interdepartamental de Estadística y Cartografía de Andalucía, 2016: 45) 
Bepsy Cedeño-Montoya, Consuelo Alfaro-Chavarría. Herramientas GNSS en la Enseñanza de Geografía y Cartografía: Aspectos Metodológicos

Para cada día de medición se identificó y descargó el archivo de efeméride precisa, también denominado órbita final.

Tabla 3: Fechas de las mediciones y sus correspondientes días según calendario GNSS, junto con el nombre de cada archivo descargado de las órbitas precisas.

\begin{tabular}{|l|l|l|l|l|}
\hline \multicolumn{1}{|c|}{ Red } & \multicolumn{1}{c|}{ Fechas de Medición } & \multicolumn{1}{c|}{ Día GNSS } & \multicolumn{1}{c|}{ Semana GPS } & \multicolumn{1}{c|}{ Orbitas finales } \\
\hline Heredia & 24 de julio & 205 & 1854 & igs18545.sp3 \\
\hline Heredia & 31 de julio & 212 & 1855 & igs18555.sp3 \\
\hline COD & 7 de agosto & 219 & 1856 & igs18565.sp3 \\
\hline COD & 21 de agosto & 233 & 1858 & igs18585.sp3 \\
\hline
\end{tabular}

Fuente: Elaboración propia a partir de datos descargados.

Las órbitas finales (IGS, 2017), se descargaron en formato sp3 (automáticamente legible por el TBC) y se almacenaron en una carpeta desde la que se importaron.

En resumen, en el post-procesamiento se utilizaron los datos GNSS resultado de las mediciones, los puntos con las coordenadas de las estaciones de medición continua y las efemérides precisas. Como se mencionó unos párrafos atrás, la finalidad de realizar este post-procesamiento es aumentar la precisión de las coordenadas de los sitios medidos, lo que se logró mediante la aplicación de dos herramientas del TBC: el procesamiento de líneas base y el ajuste de red.

De acuerdo con la Guía del usuario Trimble ${ }^{\circledR}$ Business Center (2005), el procesamiento de líneas base busca superposiciones en los tiempos de medición para calcular la media de las coordenadas, determinando las coordenadas de más alta calidad para cada punto del proyecto.

Tras revisar, corregir y aceptar los resultados del procesamiento de líneas base, y antes de continuar con el ajuste final de la red, se editaron las coordenadas de las de las estaciones de medición continua utilizadas (AACR, CRCP, ETCG y RIDC) a partir de las soluciones semanales finales de las estaciones pertenecientes a la red SIRGAS que pueden ser consultadas y descargadas en formato *.CRD (SIRGAS, 2017).

Las coordenadas semanales del marco de referencia SIRGAS (red continental + redes nacionales de referencia) son obtenidas de la combinación de las soluciones individuales proporcionadas por los Centros de 
Procesamiento SIRGAS (SIRGAS, 2017), entre los que se encuentra el CNPDG - UNA, y “detallan coordenadas de precisión milimétrica (asociadas a una época específica de referencia) y sus cambios a través del tiempo (velocidades de las estaciones) para cada estación, lo cual garantiza su orientación permanente dentro del mismo sistema de coordenadas al que se refieren los satélites GNSS" (IGAC, 2016).

Al tratarse de soluciones semanales es necesario conocer a que semana GPS corresponde el día en que se realizó la medición, y como se mencionó unas páginas atrás, esto se determinó consultando el calendario GNSS. (ver tabla 4)

Tabla 4: Fechas de las mediciones y sus correspondientes días y semana según calendario GNSS.

\begin{tabular}{|c|c|c|c|}
\hline Red & Fechas de Medición & Día GNSS & Semana GPS \\
\hline Heredia & 24 de julio & 205 & 1854 \\
\hline Heredia & 31 de julio & 212 & 1855 \\
\hline COD & 7 de agosto & 219 & 1856 \\
\hline COD & 21 de agosto & 233 & 1858 \\
\hline
\end{tabular}

Fuente: Elaboración propia a partir del Calendario GNSS, http://www.gnsscalendar.com/

Las coordenadas que ofrece esta solución semanal están dadas en coordenadas cartesianas que deben pasar una serie de transformaciones para llegar a las coordenadas elipsoidicas, para WGS84 que se puedan ingresar como coordenadas locales. Este proceso se realizó con la ayuda de las hojas de cálculo para transformaciones del país elaboradas por el CNPDG,

Los datos descargados de las soluciones semanales de SIRGAS están en coordenadas cartesianas que deben transformarse a coordenadas elipsoídicas para WGS84, utilizando la hoja de cálculo denominada "xyz flh_wgs84" (CNPDG, 2017).

A continuación en tabla 5 y 6 , se muestran un ejemplo de coordenadas obtenidas a partir de la solución semanal SIRGAS para cuatro estaciones de medición continua, correspondientes a la semana GPS 1854. 
Bepsy Cedeño-Montoya, Consuelo Alfaro-Chavarría. Herramientas GNSS en la Enseñanza de Geografía y Cartografía: Aspectos Metodológicos

Tabla 5: Coordenadas cartesianas de la solución semanal SIRGAS para la semana 1854.

\begin{tabular}{|cccccc|}
\hline \multicolumn{7}{l}{ Week 1854: SIRGAS solution aligned to IGb08 (wrt igs15P1854) } & 20-AUG-15 15:48 \\
\hline LOCAL GEODETIC DATUM: IGb08 & & EPOCH: 2015-07-22 12:00:00 & \\
NUM & STATION NAME & X (M) & Y (M) & Z (M) & FLAG \\
1 & AACR 40612M001 & 644009.01839 & -6251064.26453 & 1093780.90110 & A \\
179 & CRCP 40612M002 & 643206.98314 & -6250876.63012 & 1095084.93607 & A \\
232 & ETCG 40602M001 & 645208.31806 & -6249842.13641 & 1100399.61087 & A \\
628 & RIDC 40609M001 & 651566.59455 & -6250735.95246 & 1091707.76525 & A \\
\end{tabular}

Fuente: Coordenadas semanales de las estaciones SIRGAS-CON, http://www.sirgas.org/es/sirgascon-network/coordinates/weekly-positions/

Tabla 6: Coordenadas elipsoídicas para WGS84 para la semana 1854.

\begin{tabular}{|c|c|c|c|}
\hline Estación & Latitud & Longitud & Altura \\
\hline AACR & N 9o $56^{\prime} 19.85629125$ & $\mathrm{O} 84^{\circ} 7^{`} 4.502766013$ & 1123.938887 \\
\hline CRCP & N 9o $57^{`} 03.16502977$ & $\mathrm{O} 84^{\circ} 7^{`} 30.05931782$ & 1084.393010 \\
\hline ETCG & $\mathrm{N}^{\circ} 59^{`} 58.14282003$ & O $84^{\circ} 6^{\prime} 21.2269279$ & 1193.606529 \\
\hline RIDC & N 9 $55^{\circ} 10.8647931$ & $\mathrm{O} 84^{\circ} 2^{\prime} 56.65979186$ & 1212.150907 \\
\hline
\end{tabular}

Fuente: Elaboración propia a partir de coordenadas semanales de las estaciones SIRGAS-CON, http:/www.sirgas.org/es/sirgas-con-network/coordinates/weekly-positions/

Estas coordenadas se incluyeron antes del ajuste de red con el fin de aumentar el nivel de precisión de las estaciones de medición continua y con esto las coordenadas finales que se obtendrán para los datos brutos tras el post-procesamiento. Se seleccionaron una a una cada estación y se digitaron en el cuadro de Propiedades correspondiente. Se establecieron como coordenadas locales y se indicó que poseen calidad de control.

Para finalizar el proceso de cálculo de posiciones más precisas se debe hacer el ajuste de la red, proceso que da como resultado una coordenada adicional para cada punto, misma que pasa a ser el valor final del punto. Según la Guía del usuario Trimble ${ }^{\circledR}$ Business Center (2005), la herramienta realiza un ajuste de mínimos cuadrados que asegura que no hay errores sistemáticos o severos en los datos, sino más bien errores pequeños, aleatorios y distribuidos adecuadamente.

Terminado el proceso de ajuste de red, se observó en la vista del $\mathrm{TBC}$ una serie de elipses de error que muestran gráficamente el error 
posicional (magnitud y dirección del error) de cada punto ajustado en la red. (ver figura 7)

Figura 7: Puntos, líneas base y elipses de error de la Red Heredia y estaciones de medición continua, con órbitas finales, tras el ajuste de red.

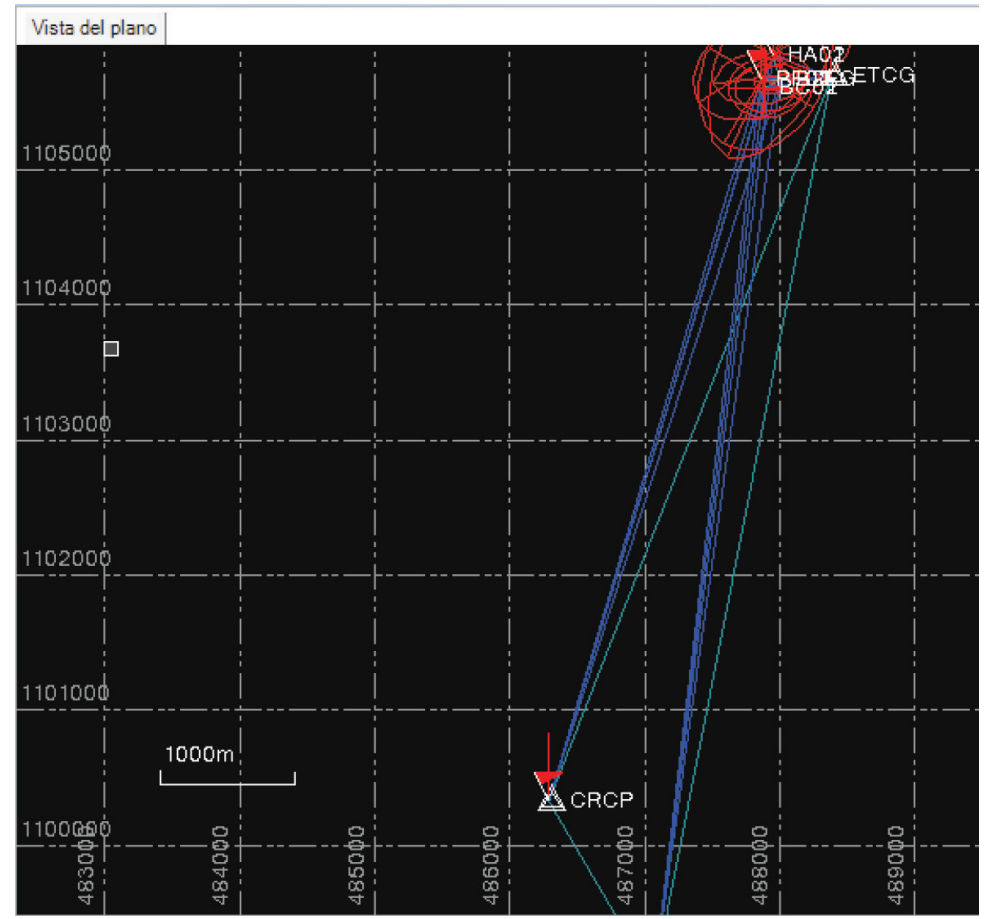

Fuente: Elaboración propia a partir de la visualización del resultado del ajuste de red en el programa TBC.

El ajuste de red ofrece también un informe en el que se muestra información general del proyecto (nombre, fecha, sistema de coordenadas), y se indican elementos estadísticos del ajuste, los valores de las coordenadas ajustadas (de cuadrícula, geodésicas y cartesianas), los errores estimados para cada punto, dimensiones de las elipses de error y una descripción del ajuste realizado a cada línea base.

Se decidió que las coordenadas obtenidas tras el post-procesamiento eran satisfactorias para el proyecto por lo que los puntos se exportaron a formato SHP, utilizando una herramienta que ofrece el TBC, lo que permitió contar con 14 puntos de control de alta precisión para el área de estudio. 
Bepsy Cedeño-Montoya, Consuelo Alfaro-Chavarría. Herramientas GNSS en la Enseñanza de Geografía y Cartografía: Aspectos Metodológicos

Sin embargo, a esta altura del proyecto, resulto evidente que la cantidad de puntos adquiridos en la Red Heredia y Campus Omar Dengo no serían suficientes para la georreferencia y ortorectificación de las fotografías aéreas, por lo que se decidió realizar una tercera campaña de medición de una segunda red para el distrito Heredia.

El trabajo de campo se realizó los días 24 y 25 de febrero del 2016, utilizando mediciones de tipo estático, donde se levantaron un total de 13 puntos de control distribuidos de la siguiente forma: Parque de Urbanización La Lilliana, Hospital San Vicente de Paul (nuevo), Cementerio de Heredia, Parque Infantil de la Urbanización La Esperanza ( $3^{\circ}$ etapa), Parque Infantil del Residencial Don Eloy, Parque Infantil de Urbanización La Amelia (La Puebla), puente sobre el río Pirro, Escuela de Enseñanza Especial (San Rafael de Heredia), Bajo Los Molinos, Escuela de Fátima, Universidad Estatal a Distancia (UNED, Mercedes Norte), plaza de Cubujuquí y Antiguo Hospital San Vicente de Paul.

Como se observa en el Mapa 3, los sitios seleccionados para esta red de apoyo se ubican en la periferia del distrito Heredia y con ellos se buscó aumentar la cantidad y mejorar la distribución de los puntos para la elaboración de un Modelo de Elevación Digital y para el trabajo con las fotografías aéreas.

Los datos crudos obtenidos tras este levantamiento estático se postprocesaron siguiendo los mismos pasos que se reseñaron para las otras dos redes, es decir, se utilizaron datos de estaciones de medición continua (ver tabla 7) y efemérides precisas (tabla 8) para ajustar las coordenadas finales de alta precisión.

Tabla 7: Fechas de las mediciones y sus correspondientes días según calendario GNSS, junto con el nombre de cada archivo descargado de las estaciones de medición continúa.

\begin{tabular}{|c|c|c|c|c|c|c|}
\hline Red & $\begin{array}{c}\text { Fechas de } \\
\text { Medición }\end{array}$ & $\begin{array}{c}\text { Día } \\
\text { GNSS }\end{array}$ & AACR & CRLP & ETCG & RIDC \\
\hline Apoyo & 24 de febrero & 55 & aacr0550 & CRLP0550 & ETCG0550 & $\begin{array}{c}03 \_30 \_2016 \\
\text { ridc055n00_092355 }\end{array}$ \\
\hline Apoyo & 25 de febrero & 56 & aacr0560 & CRLP0560 & ETCG0560 & $\begin{array}{c}03 \text { 030_2016 } \\
\text { ridc056n00_092528 }\end{array}$ \\
\hline
\end{tabular}

Fuente: Elaboración propia a partir de datos descargados. 
Bepsy Cedeño-Montoya, Consuelo Alfaro-Chavarría. GNSS Tools Used in Teaching Geography and Cartography: Methodological Aspects

Mapa 3: Distribución de los puntos de control de apoyo para la Red Heredia.

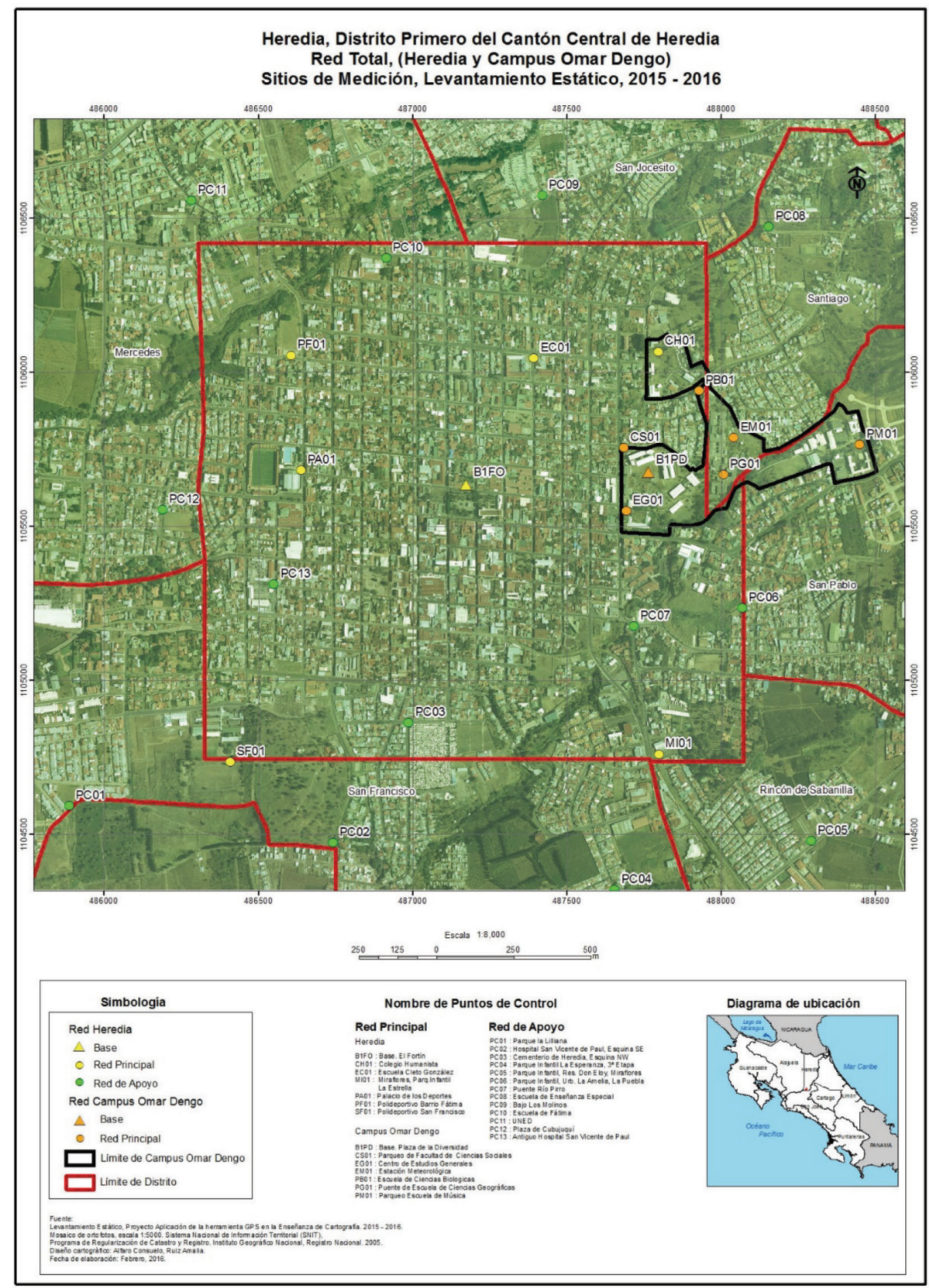


Bepsy Cedeño-Montoya, Consuelo Alfaro-Chavarría. Herramientas GNSS en la Enseñanza de Geografía y Cartografía: Aspectos Metodológicos

Tabla 8: Fechas de las mediciones y sus correspondientes días según calendario GNSS, junto con el nombre de cada archivo descargado de las órbitas precisas.

\begin{tabular}{|c|c|c|c|c|}
\hline Red & Fechas de Medición & Día GNSS & Semana GPS & Orbitas finales \\
\hline Apoyo & 24 de febrero & 55 & 1885 & igs18855.sp3 \\
\hline Apoyo & 25 de febrero & 56 & 1885 & iigs18855.sp3 \\
\hline
\end{tabular}

Fuente: Elaboración propia a partir de datos descargados.

\section{Etapa 4: Georreferencia}

Para esta etapa del proyecto se solicitó al IGN el material fotográfico aéreo crudo escala 1:1000 y 1:5000, utilizado como base para la elaboración del mosaico de ortofotos disponibles en el visor del Sistema Nacional de Información Territorial (SNIT). El IGN facilitó un total de 13 fotografías aéreas escala 1:6000, acompañadas de los reportes de calibración de las cámaras utilizadas en estos vuelos fotogramétricos y la información de posicionamiento cinemático de las líneas de vuelo PRCR-CR-017 y PRCR-CR-026.

De las 13 fotografías aéreas proporcionadas por el IGN se identificaron y seleccionaron cuatro imágenes que cubrían la totalidad del área de estudio, a saber: PRCR-CR-017_166, PRCR-CR-017_168, PRCRCR-026_055 y PRCR-CR-026_057.

Estas fotografías se georreferenciaron utilizando el software ArcGIS 10.3, específicamente, la herramienta Georreferencia, mediante la cual se logró establecer una relación de correspondencia entre las imágenes aéreas y los puntos de control generados en las anteriores etapas de este proyecto.

Para cada fotografía aérea se ubicaron entre 10 y 12 puntos de control, por lo que fue posible utilizar un polinomio de segundo orden para la asignación de las coordenadas y en promedio el RMS con el que se georreferenciaron las imágenes fue inferior a 1 metro.

Posteriormente, se delimitaron como polígono en formato shp, áreas de corte en cada fotografía que permitieran cubrir todo el ámbito de estudio y mantener la sobre posición entre ellas, con el fin de generar un mosaico que integre la cuatro imágenes. El corte y generación del mosaico se elaboraron en el programa ERDAS 2013, utilizando las herramientas Subset y Mosaic Pro del menú Raster. 


\section{Etapa 5: Ortorectificación}

La ortorectificación de las fotografías aéreas se realizó en el software ERDAS 2013, mediante el módulo IMAGINE Photogrammetry, en el cual se generaron bloques de trabajo con pares de fotografía aéreas organizados de la siguiente forma:

La creación del bloque fotogramétrico inicia con la selección del modelo geométrico que en este caso corresponde a una cámara tradicional (Frame Camera) bajo la categoría de Cámaras (Camera).

Se definió también el sistema de referencia horizontal y vertical de las imágenes aéreas, después de repasar las características de los datos con los que se cuenta para el proceso de ortorectificación, a saber:

- $\quad$ Datos procesados en el TBC: en el informe del ajuste de red se ofrecen varios juegos de coordenadas, las primeras denominadas de cuadrícula se indican las coordenadas $\mathrm{mN}, \mathrm{mE}$ para el sistema horizontal CTRM05 (variación SIRGAS) y en vertical la elevación (en metros) que corresponde a la altura ortométrica $(\mathrm{H})$. En un segundo cuadro se encuentran las coordenadas geodésicas ajustadas, en las que se visualizan coordenadas de latitud, longitud para el sistema horizontal y en vertical la altura (en metros) que se designa altura elipsoidica (h) porque depende del elipsoide de referencia, en este caso el EGM08.

- Datos de posicionamiento cinemático de las líneas de vuelo: indican las coordenadas Norte y Este para el sistema de referencia horizontal CRTM05 y la altura (en m) elipsoidica, pero asociada al elipsoide EGM96.

Es posible notar que ambos juegos de datos coinciden en el sistema de referencia horizontal, no así en el vertical. Con la intención de trabajar con una única altura elipsoidica se calculó la ondulación del geoide $(\mathrm{N})$, utilizando la herramienta calculadora EGM96 (National Geospatial - Intelligence Agency, 2015).

En esa herramienta se introdujeron los valores de coordenadas geodésicas (latitud y longitud en grados, minutos y segundos), lo que devuelve un valor correspondiente a la ondulación del geoide (N) EGM96. 
Para obtener la nueva altura ortométrica $(\mathrm{H})$ asociada al elipsoide EGM96 es necesario restarle a la altura elipsoidica (h) la ondulación del geoide, es decir, $\mathrm{H}=\mathrm{h}-\mathrm{n} .{ }^{3}$ Lo anterior permitirá que se pueda utilizar CRTM05 como sistema de referencia vertical y el EGM96 como sistema horizontal.

Tras analizar y resolver la discordancia entre datos, se procedió a definir el sistema de proyección: CRTM05, que al no estar incluido dentro de las opciones predeterminadas del programa ERDAS obligó a ingresar los siguientes parámetros:

- $\quad$ Tipo de proyección: Transversal Mercator

- Esferoide: WGS84

- Datum: Costa Rica 2005 (To WGS 84 1)

- Factor de escala: 0.999900

- $\quad$ Longitud del meridiano central: 84:00:00.0000 W

- $\quad$ Latitud del origen de la proyección: 0:00:00.0000 N

- $\quad$ Falso Este: 0.000000 metros

- $\quad$ Falso Norte: 500000.000000 metros

Inmediatamente, se definió el sistema vertical de los datos, que como se explicó anteriormente se homogenizó a EGM96, sin embargo, ERDAS 2013 no cuenta con ese sistema dentro de sus opciones, por lo que se seleccionó GRS80 que es un sistema de referencia horizontal muy similar.

De seguido se completó el cuadro de información específica de las tomas fotográficas, manteniéndose los valores por defecto para sistema de rotación (Omega, Phy, Kappa), las unidades angulares (grados) y la dirección del ángulo de toma $(Z)$. Se colocó la altura promedio de vuelo y se ingresó a la edición de la cámara.

De los reportes de calibración de cada cámara se extrajo la informacion del nombre y descripción, el valor de la distancia focal y del puntos principal Xo,Yo , de las marcas fiduciales y la distorsión de los lentes; datos que se colocaron en la edición de la cámara.

Finalizada la creación del bloque, se visualizó la ventana principal del módulo de fotogrametría de ERDAS, donde se agregaron las imágenes

3 Para más detalle respecto al tema de coordenadas horizontales se recomienda la revisión del artículo Conceptos básicos en geodesia como insumo para un tratamiento adecuado de la información geoespacial (Moya y Cedeño, 2016). 
a ortorectificar. Se seleccionaron tres imágenes de cada línea de vuelo, específicamente, la PCRC-CR-026-055, PCRC-CR-026-056 y PCRCCR-026-055. En un segundo bloque se ortorectificaron las fotografías aéreas PCRC-CR-017-166, PCRC-CR-017-167 y PCRC-CR-017-168.

Se inició con la definición de la orientación interna, posicionando cada una de las marcas fiduciales sobre las imágenes y manteniendo el orden indicado en las fotografías. Luego se continuó con la orientación externa del bloque de imágenes, proceso realizado con la herramienta Classic Point Measurement, ventana de trabajo en la que las fotografías aéreas se trabajan en pares, es decir, se seleccionaron primeros dos fotografías aéreas continuas y luego el otro par.

Se identificaron en las imágenes los sitios en los que se había realizado al medición GNSS estática, pues para estos sitios se contaba con puntos de calidad control generados específicamente para la ortorectificación. Se colocaron puntos en el primer par, otros en el segundo par y para cada uno se anotó el valor de las coordenada $\mathrm{X}, \mathrm{Y}$ y $\mathrm{Z}$ ajustada y se les definió como puntos de tipo FULL (certeza de la coordenada X,Y,Z) y de Control (por la calidad).

Adicionalmente, se permitió que el programa agregará automáticamente una serie de puntos en común (TIE points) en las tres imágenes, de los que se eliminaron aquellos localizados en techos o sombras, indicando que correspondían a tipo HORIZONTAL (confianza solo en las coordenadas X, Y) y manteniendo la clasificación en TIE.

Dentro del mismo módulo de definición de la orientación externa, se accedió a la Aerotriangulación, logrando la convergencia de los puntos y en la que se alcanzó un RMS de 21.0108 pixeles. Así, se completó la orientación externa de las imágenes y se observó cómo las fotografías aéreas se posicionaron de acuerdo a los puntos de control colocados, traslapándose. 
Figura 8: Ventana principal del módulo IMAGINE Photogrammetry de ERDAS, después de completar la orientación interna y externa.

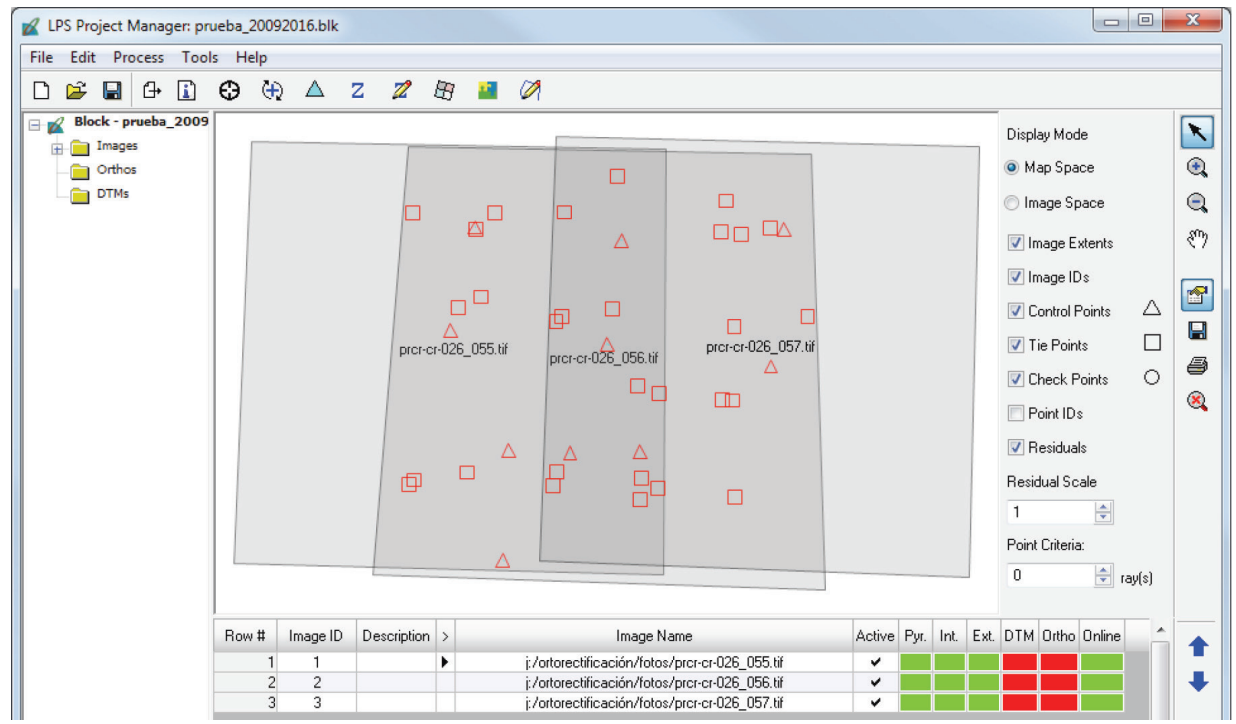

Fuente: Visualización del proceso de ortorectificación en el módulo IMAGINE Photogrammetry de ERDAS.

Se avanzó hacia el proceso de generación del Modelo de Elevación Digital (MDE) que complementó la información de elevación necesaria para la ortorectificación de las fotografías aéreas. El MDE se generó con una resolución espacial de $2 \mathrm{~m}$, utilizando como base los 27 puntos de control generados en el levantamiento GNSS.

Finalmente, se llegó a la generación de las imágenes ortorectificadas, revisando que las tres imágenes de cada bloque se incluyeran y manteniendo como sistema de proyección de salida el CRTM05. El MDE generado para el primer bloque fue el mismo utilizado para la ortorectificación del segundo bloque.

Se obtuvieron así dos mosaicos de fotografías aéreas ortorectificadas que se integraron en un único mosaico utilizando la herramienta Mosaic Pro del menú Raster.

\section{Resultados}

El producto principal obtenido a partir de la metodología reseñada en el apartado anterior es el conjunto de 27 puntos de control con coordenadas 
ajustadas al sistema horizontal CRTM05 (marco de referencia SIRGAS, época 2015,19 y el datum IGb08) y vertical EGM08.

Se muestran a continuación tres tablas con las coordenadas finales (horizontales y verticales) calculadas a partir del ajuste de red, con sus respectivos errores en metros.

Tabla 9: Red Heredia - Coordenadas y elevación ajustadas al sistema horizontal CRTM05 (marco de referencia SIRGAS, época 2015,19 y el datum IGB08) y sistema vertical EGM08.

\begin{tabular}{|l|c|c|c|c|c|c|c|}
\hline \multicolumn{1}{|c|}{ Nombre del punto } & $\begin{array}{c}\text { Código } \\
\text { del } \\
\text { Punto }\end{array}$ & $\begin{array}{c}\text { Coordenada } \\
\text { Este } \\
\text { SIRGAS }\end{array}$ & $\begin{array}{c}\text { Error } \\
\text { Este } \\
(\mathbf{m})\end{array}$ & $\begin{array}{c}\text { Coordenada } \\
\text { Norte } \\
\text { SIRGAS }\end{array}$ & $\begin{array}{c}\text { Error } \\
\text { Norte } \\
(\mathbf{m})\end{array}$ & $\begin{array}{c}\text { Elevación } \\
(\mathbf{m})\end{array}$ & $\begin{array}{c}\text { Error de } \\
\text { Elevación } \\
(\mathbf{m})\end{array}$ \\
\hline El Fortin & B1FO & 487173.665 & 0.034 & 1105633.788 & 0.025 & 1153.848 & 0.076 \\
\hline Colegio Humanista & CH01 & 487796.741 & 0.028 & 1106065.446 & 0.023 & 1169.897 & 0.081 \\
\hline Escuela Cleto González & EC01 & 487393.519 & 0.030 & 1106043.860 & 0.026 & 1174.881 & 0.077 \\
\hline Polidevortivo Fátima & PF01 & 486606.080 & 0.045 & 1106053.502 & 0.038 & 1144.465 & 0.102 \\
\hline Palacio de los Deportes & PA01 & 486639.005 & 0.073 & 1105680.743 & 0.050 & 1142.061 & 0.124 \\
\hline Polideportivo San Francisco & SF01 & 486409.142 & 0.049 & 1104733.676 & 0.037 & 1120.171 & 0.120 \\
\hline Parque Infantil Miraflores & MI01 & 487799.991 & 0.037 & 1104759.050 & 0.029 & 1132.064 & 0.094 \\
\hline
\end{tabular}

Fuente: Elaboración propia a partir del informe de ajuste de red generado en el programa TBC.

Tabla 10: Red Campus Omar Dengo - Coordenadas y elevación ajustadas al sistema horizontal CRTM05 (marco de referencia SIRGAS, época 2015,19 y el datum IGB08) y sistema vertical EGM08

\begin{tabular}{|l|c|c|c|c|c|c|c|}
\hline \multicolumn{1}{|c|}{ Nombre del punto } & $\begin{array}{c}\text { Código } \\
\text { del } \\
\text { Punto }\end{array}$ & $\begin{array}{c}\text { Coordenada } \\
\text { Este } \\
\text { SIRGAS }\end{array}$ & $\begin{array}{c}\text { Error } \\
\text { Este } \\
(\mathbf{m})\end{array}$ & $\begin{array}{c}\text { Coordenada } \\
\text { Norte } \\
\text { SIRGAS }\end{array}$ & $\begin{array}{c}\text { Error } \\
\text { Norte } \\
(\mathbf{m})\end{array}$ & $\begin{array}{c}\text { Elevación } \\
(\mathbf{m})\end{array}$ & $\begin{array}{c}\text { Error de } \\
\text { Elevación } \\
(\mathbf{m})\end{array}$ \\
\hline Plaza de la Diversidad & B1PD & 487765.122 & 0.014 & 1105675.783 & 0.011 & 1151.021 & 0.029 \\
\hline Parqueo Ciencias Sociales & CS01 & 487684.872 & 0.012 & 1105753.891 & 0.011 & 1158.223 & 0.03 \\
\hline Estudios Generales & EG01 & 487693.275 & 0.015 & 1105549.658 & 0.013 & 1149.143 & 0.04 \\
\hline Puente Geografía & PG01 & 488008.136 & 0.016 & 1105667.131 & 0.017 & 1148.719 & 0.05 \\
\hline Parqueo Biología & PB01 & 487928.612 & 0.018 & 1105938.217 & 0.016 & 1167.619 & 0.035 \\
\hline Estación Meteorológica & EM01 & 488041.117 & 0.013 & 1105785.682 & 0.009 & 1158.093 & 0.024 \\
\hline Parqueo Escuela de Música & PM01 & 488450.134 & 0.012 & 1105763.571 & 0.010 & 1172.595 & 0.026 \\
\hline
\end{tabular}

Fuente: Elaboración propia a partir del informe de ajuste de red generado en el programa TBC. 
Bepsy Cedeño-Montoya, Consuelo Alfaro-Chavarría. Herramientas GNSS en la Enseñanza de Geografía y Cartografía: Aspectos Metodológicos

Tabla 11: Red de Apoyo Heredia - Coordenadas y elevación ajustadas al sistema horizontal CRTM05 (marco de referencia SIRGAS, época 2015,19 y el datum IGB08) y sistema vertical EGM08.

\begin{tabular}{|l|c|c|c|c|c|c|c|}
\hline \multicolumn{1}{|c|}{ Nombre del punto } & $\begin{array}{c}\text { Código } \\
\text { del } \\
\text { Punto }\end{array}$ & $\begin{array}{c}\text { Coordenada } \\
\text { Este } \\
\text { SIRGAS }\end{array}$ & $\begin{array}{c}\text { Error } \\
\text { Este } \\
(\mathbf{m})\end{array}$ & $\begin{array}{c}\text { Coordenada } \\
\text { Norte } \\
\text { SIRGAS }\end{array}$ & $\begin{array}{c}\text { Error } \\
\text { Norte } \\
(\mathbf{m})\end{array}$ & $\begin{array}{c}\text { Elevación } \\
(\mathbf{m})\end{array}$ & $\begin{array}{c}\text { Error de } \\
\text { Elevación } \\
(\mathbf{m})\end{array}$ \\
\hline Parque La Lilliana & PC01 & 485884.937 & 0.033 & 1104587.362 & 0.026 & 1110.758 & 0.056 \\
\hline Hospital nuevo & PC02 & 486740.577 & 0.029 & 1104469.600 & 0.021 & 1106.957 & 0.050 \\
\hline Cementerio & PC03 & 486985.947 & 0.040 & 1104860.048 & 0.029 & 1124.964 & 0.076 \\
\hline Parque Infantil La Esperanza & PC04 & 487657.239 & 0.035 & 1104317.706 & 0.024 & 1111.804 & 0.096 \\
\hline Parque Infantil Res. Don Eloy & PC05 & 488292.229 & 0.024 & 1104476.398 & 0.017 & 1149.223 & 0.063 \\
\hline Parque Infantil La Amelia & PC06 & 488069.216 & 0.017 & 1105231.819 & 0.014 & 1137.956 & 0.054 \\
\hline Pirro & PC07 & 487717.684 & 0.017 & 1105174.395 & 0.016 & 1126.067 & 0.037 \\
\hline Escuela Enseñanza Especial & PC08 & 488155.531 & 0.015 & 1106469.745 & 0.015 & 1219.938 & 0.033 \\
\hline Bajo Los Molinos & PC09 & 487420.835 & 0.019 & 1106570.452 & 0.016 & 1184.353 & 0.045 \\
\hline Escuela Fátima & PC10 & 486915.067 & 0.023 & 1106367.857 & 0.018 & 1157.489 & 0.057 \\
\hline UNED & PC11 & 486284.670 & 0.026 & 1106552.572 & 0.020 & 1154.684 & 0.104 \\
\hline Plaza Cubujuqui & PC12 & 486190.032 & 0.028 & 1105550.404 & 0.023 & 1122.486 & 0.078 \\
\hline Hospital Viejo & PC13 & 486549.321 & 0.022 & 1105307.652 & 0.019 & 1134.352 & 0.048 \\
\hline
\end{tabular}

Fuente: Elaboración propia a partir del informe de ajuste de red generado en el programa TBC.

Tras la revisión y el análisis del informe del ajuste de red se concluyó que los valores de coordenadas obtenidos eran suficientes para los fines del proyecto. Los errores en horizontal tienen en promedio $2.68 \mathrm{~cm}$ en el Este, $2.12 \mathrm{~cm}$ en el Norte y en vertical de $6.29 \mathrm{~cm}$. Todos los valores se encuentran por debajo de la precisión horizontal ( $3 \mathrm{~mm}+0,1 \mathrm{ppm}$ RMS $)$ y vertical (3,5 mm + 0,4 ppm RMS) indicadas en la hoja de datos del equipo Trimble ${ }^{\circledR}$ R4 GNSS para levantamientos estáticos de alta precisión.

Otro de los productos generados en el proyecto es el mosaico de fotografías aéreas georreferenciadas. En la metodología se señaló que las cuatro fotografías aéreas seleccionadas fueron georreferenciadas utilizando de 10 a 12 puntos de control, con un polinomio de segundo orden y un error promedio de $1 \mathrm{~m}$.

Sin embargo, al comparar las fotografías georreferenciadas con el mosaico de ortofotos, escala 1:5000, disponible en el Sistema Nacional de Información Territorial (SNIT), los desplazamientos alcanzan un máximo de 3 metros, especialmente en dirección noreste. 
Figura 9: Visualización del mosaico de fotografías aéreas georreferenciadas en la vista de ArcMap, del ArcGIS.

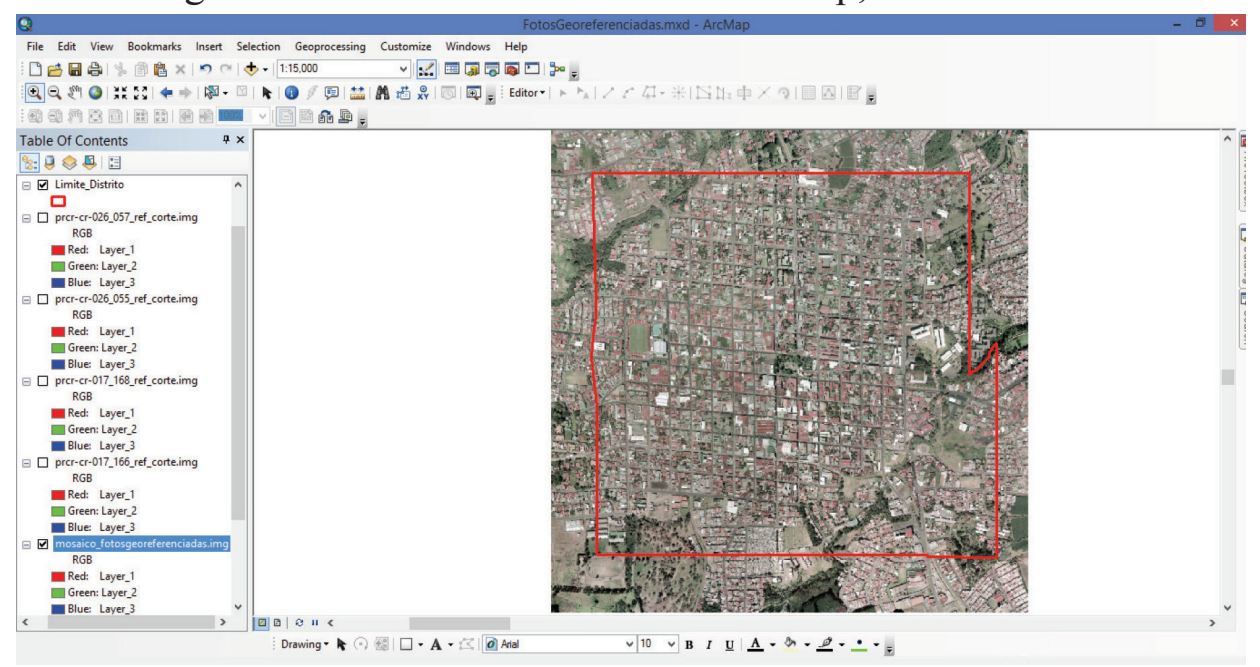

Fuente: Elaboración propia partir de la Visualización mosaico de fotografías aéreas georreferenciadas en la vista del ArcMap, ArcGIS 10.4

Los desplazamientos señalados son esperados, pues la georeferencia no ofrece el mismo nivel de precisión y corrección de la fotografía aérea como si lo hace el proceso de ortorectificación. Se debe recordar que la georreferenciación es "el uso de coordenadas de mapa para asignar una ubicación espacial a entidades cartográficas" (ArcGIS Resources, 2016), proceso que se realiza a partir de un archivo vectorial (puntos, líneas o polígonos) y que traslada la información de coordenadas horizontales a un dato que no las tiene.

Al no utilizarse información de elevaciones $(Z)$ la corrección de la fotografía aérea no es completa, pues aunque adquiere una posición en $X$, Y no se eliminan los desplazamientos producto de la proyección central inherente a las imágenes aéreas por su forma de adquisición.

Adicional al desplazamiento horizontal de 3 metros que se observó en el mosaico georreferenciado, hay un desplazamiento aparente que tiene su causa campo angular de la cámara fotográfica con la que tomo la fotografía y su proyección central. Es decir, el objeto está bien posicionado geográficamente pero el ángulo en el que se tomó la fotografía hace que parezca desplazado. 
Bepsy Cedeño-Montoya, Consuelo Alfaro-Chavarría. Herramientas GNSS en la Enseñanza de Geografía y Cartografía: Aspectos Metodológicos

Figura 10: Visualización del desplazamiento aparente de los objetos en la imagen georeferenciada comparada con el mosaico de ortofotos, escala 1:5000, disponible en el SNIT.

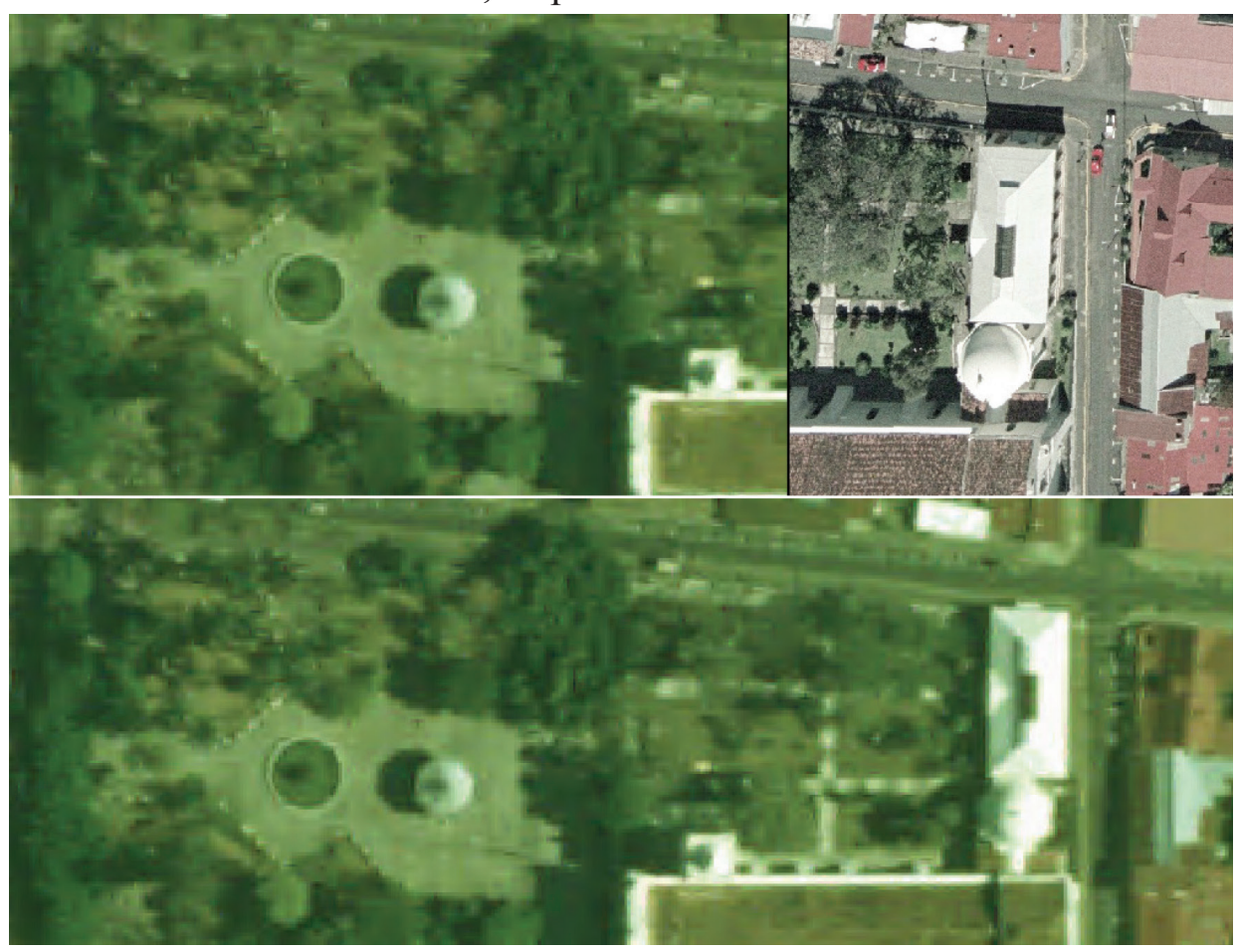

Fuente: Elaboración propia partir de la visualización mosaico de ortofotos en la vista del ArcMap, ArcGIS 10.4

El proyecto generó también un mosaico de fotografías aéreas ortorectificadas, generado en el software ERDAS a partir de seis imágenes, tres de cada línea de vuelo, para abarcar así toda el área del distrito Heredia.

La ortorectificación de las imágenes utilizó los 27 puntos de control generados en el levantamiento GNSS para la orientación externa y para el MDE, alcanzado un error promedio de $2.5 \mathrm{~m}$, según indicó el resultado del proceso de aerotriangulación. 
Figura 11: Visualización del mosaico de fotografías aéreas georreferenciadas en la vista de ArcGIS.

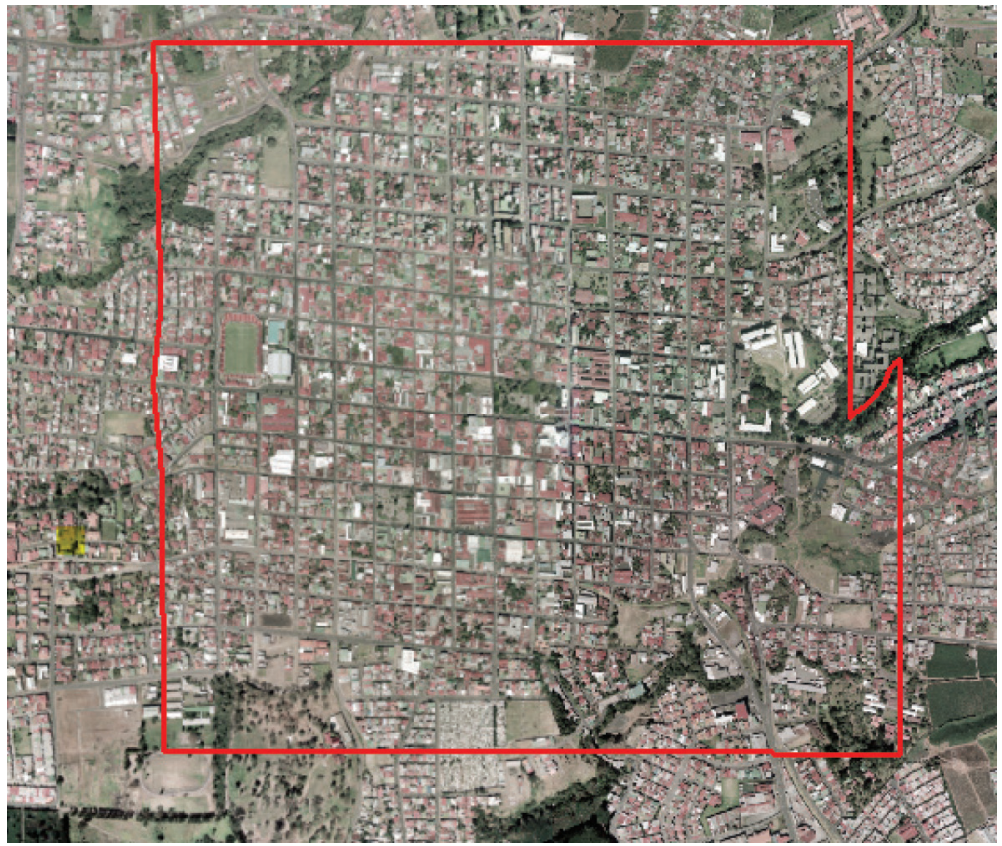

Fuente: Elaboración propia partir de la visualización mosaico de ortofotos en vista del ArcMap, ArcGIS 10.4

Al comparar las fotografías aéreas ortorectificadas en el proyecto con el mosaico de ortofotos, escala 1:5000, disponible en el Sistema Nacional de Información Territorial (SNIT), los desplazamientos alcanzan un máximo de 3 metros en los extremos del área de estudio y menos de $1 \mathrm{~m}$ en la parte central del mosaico.

La metodología seguida permitió alcanzar exitosamente los productos propuestos al formular el proyecto. Los datos permiten que el ejercicio pueda ser replicado, por partes o de forma completa, en los cursos del área de Ciencias de la Información Geográfica (CIG) que se imparten en la ECG.

\section{Conclusiones y recomendaciones}

El proyecto "Aplicación de la herramienta GPS en la enseñanza de Cartografía" se formuló con la clara intención de definir una metodología para una línea de trabajo en el tema de levantamiento de datos con 
herramientas GNSS, que permitiera generar productos y datos aplicables a distintos temas de los cursos del área de CIG, específicamente, los asociados a la producción cartográfica.

Además de alcanzar los productos planteados, mediante el proyecto se adquirieron una serie de conocimientos que contribuirán a mejorar la docencia y la investigación de la ECG.

Uno de los primeros puntos aclarados en la ejecución del proyecto fue el concepto de GNSS y los distintos sistemas que lo componen (GPS, Glonass, Galileo, Beidou), lo que a su vez permitió comprender las diferencias entre posicionamiento absoluto y relativo, características y tipos de dispositivos, así como entender la adecuada selección del tipo de posicionamiento según la tarea a realizar. La técnica más sencilla de posicionamiento es el absoluto con código, en el que se utilizan navegadores conocidos como GPS, cuya precisión aproximada es de $5 \mathrm{~m}$ y es la herramienta de mayor uso por su facilidad y disponibilidad, hasta en teléfonos celulares. El posicionamiento relativo o diferencial es una técnica más compleja, en la que se requiere de equipo especializado, con mayor costo de adquisición y un nivel de conocimiento adecuado para su utilización. Los resultados de estas observaciones son muchos más precisos (centimétricos o milimétricos), dependiendo del método de observación y complejidad de la red de medición planificada (Brunini, 2010).

Otro de los aspectos fundamentales a considerar cuando se trabaja con equipo GNSS es la planificación del trabajo de campo, que implica la selección del método de observación, la precisión requerida según el objetivo del trabajo, la definición de la red de medición, la selección de los sitios a utilizar como puntos de control y la aplicación de los datos a generar.

También es importante recordar que según el método de observación seleccionado será necesario incorporar el post-procesamiento de datos GNSS, tarea de gran complejidad que implica conocimiento especializado, así como la adquisición del software compatible con el equipo usado, comprensión sobre la calidad, fuentes y formatos de los datos necesarios para realizar el proceso.

El uso de este tipo de herramientas adquiere mayor relevancia cuando se sabe que en Costa Rica hay gran dificultad para acceder a datos espaciales confiables y actualizados, por lo que la posibilidad de generar datos propios de alta calidad y precisión es siempre importante. 
Se debe recordar que la ECG cuenta con el equipo Trimble ${ }^{\circledR} \mathrm{R} 4$, por lo que se recomienda su aplicación en la docencia y la investigación, incorporando contenidos sobre GNSS inicialmente en los cursos Cartografía I, Cartografía Temática y Fotointerpretación, para luego ir avanzando gradualmente al resto del área CIG, lo que permitirá que el tema se convierta en un eje transversal en la malla curricular de las carreras. Para esto es necesaria la definición y materialización de una red fija para medición en la UNA, pues muchos de los puntos marcados y medidos en el Campus Omar Dengo fueron eliminados por procesos de construcción y remodelación de infraestructura. Además, se propone una red fija para medición en el distrito de Heredia, autorizada por la Municipalidad de Heredia para su beneficio y el de otras unidades académicas de la UNA.

Finalmente, desde el punto de vista de las participantes, se considera un proyecto exitoso, pues se cumplió con todos los objetivos y actividades propuestas, y el aprendizaje alcanzado fue mucho más allá de lo que originalmente se había pensado (pronosticado).

\section{Agradecimientos}

Al Dr. Jorge Moya Zamora, responsable del Centro Nacional de Procesamiento de Datos Geoespaciales (CNPDG) de la Escuela de Topografía Catastro y Geodesia (ETCG) de la UNA, quién muy amable y desinteresadamente brindó una capacitación a los integrantes de este proyecto en los meses de marzo a junio de 2015 y asesoramiento a lo largo de los dos años de ejecución del proyecto. Definitivamente sin su ayuda no habría sido posible alcanzar muchas de las metas de este proyecto.

Al Consejo Municipal de cantón Central de Heredia por autorizar la colocación del equipo de medición en espacios de propiedad municipal.

\section{Referencias}

ArcGIS Resources. (2016). Georreferenciación y sistemas de coordenadas. Recuperado de http://resources.arcgis.com/es/help/getting-tarted/ articles/026n0000000s000000.htm Consultado el 17 de enero de 2017 Brunini, C., Sánchez, L., Dalda, A., Cano, M. A., Sánchez, J. A., Valdés, M. \& López, P. G. (2010). Apuntes del X Curso de GPS en Geodesia y Cartografía. Instituto Geográfico Nacional de España y Agencia de Cooperación Española. Montevideo, Uruguay. 
Centro Nacional de Procesamiento de Datos GNSS (CNPDG). (2017). xyz_flh_wgs84 (hoja de cálculo). Universidad Nacional. Heredia, Costa Rica. Recuperado de http://www.cnpdg.una.ac.cr/index.php/ download/software/transformaciones-cr/category/6-transcr. Consultado en mayo de 2015

Comisión Interdepartamental de Estadística y Cartografía de Andalucía. (2011). NTCA 02002 Observación y procesamiento GNSS. Normas técnicas cartográficas de Andalucía. Junta de Andalucía. Sevilla España. Recuperado de https://www.juntadeandalucia.es/institutodeestadisticaycartografia/ieagen/sea/ntca/02_procesos/02002_Observacion_procesamiento.pdf. Consultado el 20 de noviembre de 2016.

García, D. (2008). Sistema GNSS (Global Navigation Satellite System). (Proyecto de fin de carrera). Escuela Politécnica Superior. Universidad Autónoma de Madrid. Madrid, España. 104 p.

Instituto Geográfico Agustín Codazzi (IGAC). (2016). Red MAGNA ECO. Recuperado de http://www.igac.gov.co/wps/portal/igac/raiz/iniciohome/TramitesServicios/FueraDeServicio/!ut/p/c4/04_SB8K8xLLM9MSSzPy8xBz9CP0os3hHT3d_JydDRwN3A083A08jJ1MD 1xBXYwsnE_2CbEdFAGrs9jg!/?WCM_PORTLET=PC_7_AIGOBB1A0G0IF0I2B50DTE38R4_WCM\&WCM_GLOBAL_ CONTEXT=/wps/wcm/connect/We-b+-+Tramites+y+Servicios/ Servicios/Servicios/Informacion+Geodesica/Red+MAGNA+ECO/. Consultado el 21 de noviembre de 2016.

International GNSS Service (IGS). (2017). IGS Product Availability. Recuperado de https://igscb.jpl.nasa.gov/components/prods_cb.html Consultado en mayo de 2015.

Jahic, E. (2016). GNSS Calendar and Utility. Recuperado de http://www. gnsscalendar.com/. Consultado en mayo de 2015.

National Geospacial - Intelligence Agency (NGA). (2015). NGA EGM96 Geoid Calculator. Recuperado de http://earth-info.nga.mil/GandG/wgs84/ gravitymod/egm96/intpt.html. Consultado el 30 de mayo de 2016.

Trimble ${ }^{\circledR}$. (2005). Manual de Referencia Trimble ${ }^{\circledR}$ Business Center Heavy Construction Edition, Versión 1.20. Ohio, EEUU: Trimble Navigation Limited.

Trimble ${ }^{\circledR}$. (2005). Guía del usuario Trimble ${ }^{\circledR}$ Business Center. Ohio, EEUU: Trimble Navigation Limited. 
Trimble ${ }^{\circledR}$. (2009). Hoja de datos Sistema GPS Trimble ${ }^{\circledR}$ R4. Ohio, EEUU: Trimble Navigation Limited.

Sistema de Referencia Geocéntrico para las Américas (SIRGAS (2017.) SIRGAS de operación continua Consultado en mayo de 2015. http:// www.sirgas.org/es/sirgas-con-network/stations/station-list/

Sistema de Referencia Geocéntrico para las Américas (SIRGAS). (2017). Coordenadas semanales de las estaciones SIRGAS-CON. Recuperado de http://www.sirgas.org/index.php?id=153 Consultado en mayo de 2015. 